\title{
What matters to you? Embracing shared decision making in ophthalmology
}

\author{
Rashmi G. Mathew $\mathbb{( D}^{1} \cdot$ Hannah M. Timlin ${ }^{2} \cdot$ Caroline J. MacEwen $\mathbb{D}^{3}$
}

Received: 30 December 2020 / Revised: 6 January 2021 / Accepted: 11 January 2021 / Published online: 29 January 2021

(c) The Author(s), under exclusive licence to The Royal College of Ophthalmologists 2021

"If I'd known that doctor, I would never have had the operation". The voice of a regretful elderly patient, following the difficulties of using frequent eyedrops and having frequent visits to the hospital following her glaucoma surgery.

'No decision about me, without me' [1], has been pivotal for healthcare; emphasising the importance for each patient to be involved in making informed choices about their own care as a means of securing better care for them as an individual—and hence better outcomes. Decision-making becomes a joint responsibility between doctor and patientand shared decision making (SDM) is the process whereby the most suitable decision for a particular patient is made by bringing together the best available medical evidence and the patient's personal values and preferences [2].

The exchange of information between doctors and patients is central to this and it behoves the doctor to unearth the patient's values and simultaneously explain the options and communicate risk in a form that is tangible to each patient. This should include the option to 'do nothing' - as the patient should not feel compelled to undergo any form of active intervention. The 'Choosing Wisely UK' initiative introduced a simple mnemonic 'BRAN', for use in consultations, to ensure that all relevant information is discussed with patients in consultations. BRAN stands for 'Benefits', 'Risks', 'Alternatives' and do 'Nothing' [3]. The mnemonic has been expanded to reflect the challenges of decision making during COVID-19 to

Rashmi G. Mathew

Rashmi.mathew1@nhs.net

1 Department of Glaucoma, Moorfields Eye Hospital NHSFT, London, UK

2 Adnexal Department, Moorfields Eye Hospital NHSFT, London, UK

3 Ninewells Hospital and Medical School, University of Dundee, Dundee, UK
'BRAND', where the ' $\mathrm{D}$ ' is 'defer'; which is different to 'doing nothing', but important to be recognised during this unusual time and the risks and benefits of this option (including the risks of COVID exposure) explained.

The Montgomery ruling in 2015 was a historical ruling and probably one of the most important regarding 'consent' and 'choice' for patients [4]. It enshrined in law that doctors have a duty to advise patients about all material risks including those to which a specific patient may attach particular significance.

More recently, in Nov 2020, the General Medical Council released guidance [5], underscoring the importance of consent being a process that starts from when a patient first seeks clinical input and that patients being involved in decisions about their care is paramount. It outlines the purpose for dialogue between doctors and patients:

(1) to help the patient understand their role in the process, and their right to choose whether or not to have treatment or care.

(2) to make sure the patient has the opportunity to consider relevant information that might influence their choice between the available options.

(3) to try and reach a shared understanding of the expectations and limitations of the available options.

Currently, draft NICE guidance on SDM is out for review and proposes that SDM is ubiquitously embedded in healthcare delivery through training and robust governance procedures; recognising that this is an essential aspect of contemporary medical practice.

Communication of options and risks can be challenging, and it is important to remember that about half of adults in the UK have low or marginal health literacy. Health literacy is important as it affects a patient's ability to explore options and ask questions, and their capacity to understand risk [6]. A lack of understanding about surgical procedures and their implications [7] is recognised in a significant proportion of patients, even after they have agreed to surgery and consent 
has been confirmed [6]. Patients are also influenced by their emotions [8] and their own experiences, for example: a relative who lost their vision from cataract surgery or conversely all their friends and family having excellent outcomes following cataract surgery.

In addition, patients and clinicians tend to understand probability and risk differently, with clinicians considering statistical probabilities across a population, whereas patients consider them as all or nothing events for themselves. When explaining risk, it is also important to consider everyday examples in order for the patient be able to attach significance. For example, if everyone on a full double-decker bus had cataract surgery, only one would require a second operation due to complications. Some authors have also associated medical risk with car crashes and winning the lottery [9].

Evidence suggests that SDM, when done well, enhances patient experience, improves treatment adherence and outcomes and is associated with fewer risks of treatment regret [2]. Patient choice is an imperative in modern medicine and with so many new treatments, interventions and surgical options in ophthalmology, it is a collective responsibility to improve the quality of service we provide by understanding and embracing SDM.

Although this might be termed 'just good medicine' there remains a huge variation in comprehension and delivery by the profession during direct clinical care. A significant barrier to this is a lack of professional education and training; core or specialist competences in SDM do not, as yet, exist. Raising professional awareness and providing educational support are currently key. In order to help address this in ophthalmology, a 4-unit e-learning module on SDM has been developed specifically for this specialty, with the aim of improving the ability of ophthalmic healthcare workers to better communicate risk [https://porta 1.e-lfh.org.uk/Component/Details/604821]. Using ophthalmic specific examples, simple evidence-based strategies are used to ensure that delivery of information is balanced and standardised; such as use of absolute risk rather than relative risk, the use of common denominators when explaining risk and the importance of pictorial representation, such as patient decision aids. This course has been evaluated and been found to increase the confidence of clinicians to facilitate SDM and to improve their knowledge regarding the principles of risk communication [10].

Author contributions RGM, HMT and CJM drafted and finalised the manuscript.

\section{Compliance with ethical standards}

Conflict of interest The authors declare that they have no conflict of interest.

Publisher's note Springer Nature remains neutral with regard to jurisdictional claims in published maps and institutional affiliations.

\section{References}

1. https://assets.publishing.service.gov.uk/government/uploads/ system/uploads/attachment_data/file/216980/Liberating-the-NHSNo-decision-about-me-without-me-Government-response.pdf. Accessed Dec 2020.

2. https://www.england.nhs.uk/shared-decision-making/. Accessed Dec 2020.

3. https://www.aomrc.org.uk/choosing-wisely/. Accessed Dec 2020.

4. Montgomery (Appellant) v Lanarkshire Health Board (Respondent) (Scotland) [2015] UKSC 11.

5. https://www.gmc-uk.org/ethical-guidance/ethical-guidance-fordoctors/decision-making-and-consent\#. Accessed Dec 2020.

6. Ankuda CK, Block SD, Cooper Z, Correll DJ, Hepner DL, Lasic $\mathrm{M}$, et al. Measuring critical deficits in shared decision making before elective surgery. Patient Educ Couns. 2014;94:328-33.

7. Osborn K, Bradley J, Knox E, Leighton P. What matters to patients? A thematic analysis of patient information and support needs. Eye. 2020;34:103-15.

8. Ropeik D, Clay G. Risk! A practical guide for deciding what's really safe and what's really dangerous in the world around you. New York: N Y Houghton Mifflin; 2002.

9. Paling J. Up to your armpits in alligators: how to sort out what risks are worth worrying about. Gainesville, FL: Risk Communication and Environmental Institute; 1997.

10. Hoffmann TC, Del Mar C, Santhirapala R, Freeman A. Teaching clinicians shared decision making and risk communication online: an evaluation study. BMJ Evid Based Med. 2020. https://doi.org/ 10.1136/bmjebm-2020-111521. 